\title{
Mass Detection Using the Zernike Moments and Fast Fourier Transform (FFT) of Convex Mass Shapes on Mammogram Images
}

\section{Mamografi Görüntülerinde Dışbükey Kitle Şekillerinin Hızlı Fourier Dönüşümünü (FFT) ve Zernike Momentlerini Kullanarak Kitle Algılama}

Geliş / Received: 14/01/2021

\author{
Hatice Aydın ${ }^{1 *}$, Semih Ergin ${ }^{2}$
}

Revize / Revised: 27/04/2021

Kabul / Accepted: 18/05/2021

\begin{abstract}
In this study, mass detection application is developed for mammograms from Zernike moments and Fast Fourier Transform (FFT) of convex mass boundary. During the development of the application, the Mammographic Image Analysis Society (MIAS) database, which is available to the researchers, is used. The MIAS database contains $322,1024 \times 1024$ pixel resolution images of normal, benign, and malignant cancer. In the first phase of the study, noise reduction and image enhancement process is performed on the images. The pectoral muscles, which have similar features as region of interests (ROIs) are decomposed. After the decomposition process, images are enhanced by contrast to clarify ROIs. From ROIs, Zernike moments and FFT of convex mass boundary are calculated and feature vectors are obtained for each image. The new feature vector of each image was divided into training and test sets, and the labels of the test set were obtained with $100 \%$ accuracy.
\end{abstract}

Keywords- Breast Mass, Pectoral Muscle Removal, Support Vector Machine, Linear Discriminant Analysis

$\overline{\mathbf{O Z Z}}$

$\mathrm{Bu}$ çalışmada, mamografi görüntülerinde şüpheli bölge olarak tanımlanan bölgelerin dışbükey kitle sınırının Zernike momentlerinden ve Hizlı Fourier Dönüşümünden (FFT) faydalanarak kitle algılama uygulaması geliştirilir. Uygulamanın geliştirilmesi sırasında araştırmacıların kullanımına açık olan Mammografi Analiz Topluluğu (MIAS) veritabanı kullanılır. MIAS veritabanı, 322 adet 1024x1024 piksel çözünürlüklü normal, iyi huylu ve kötü huylu kanser mamografi görüntülerini içerir. Çalışmanın ilk aşamasında, görüntüler üzerinde gürültü azaltma ve görüntü iyileştirme işlemi yapılmaktadır. Şüpheli bölgelerle benzer özelliklere sahip olan pektoral kaslar görüntülerden ayrıştırılır. Ayrıştırma işleminden sonra, şüpheli bölgeleri netleştirmek için görüntüler kontrast yönünden iyileştirilir. Şüpheli bölgelerden, dışbükey kitle sınırının Zernike momentleri ve FFT'si hesaplanır ve her görüntü için öznitelik vektörleri elde edilir. Her bir görüntünün yeni öznitelik vektörü eğitim ve test kümelerine ayrılmış ve test kümesinin etiketleri \%100 doğruluk ile elde edilmiştir.

Anahtar Kelimeler- Meme Kitlesi, Pektoral Kas Ayrıştırma, Destek Vektör Makinası, Doğrusal Ayırma Analizi

1*Sorumlu yazar iletişim: htcaydin@ankara.edu.tr (https://orcid.org/0000-0002-7355-9329)

Elektrik ve Enerji Bölümü, Ankara Üniversitesi, Gümüşdere Ziraat Yerleşkesi, 06120, Ankara, Türkiye

2İletişim: sergin@ogu.edu.tr (https://orcid.org/0000-0002-7470-8488)

Elektrik ve Elektronik Mühendisliği, Eskişehir Osmangazi Üniversitesi, Meşelik Kampüsü, 26480, Eskişehir, Türkiye 


\section{INTRODUCTION}

Breast cancer is one of the leading causes of female death, but early diagnosis and mortality of breast cancer can be reduced [1]. Breast cancer screening methods include self-examination, clink examination, mammography, ultrasound imaging, magnetic resonance imaging, and tissue aspiration. During this study, mammography images, which are one of the methods used for cancer diagnosis, are examined. During mammography, not only the breast area, but also pectoral muscles are displayed.

Because of the use of Computer Aided Detection (CADe) and Computer Aided Diagnosis (CADx) systems, it is possible to monitor and review the points that can be overlooked by the specialist. CADe systems determine suspicious areas for breast cancer from mammography images, while CADx systems determine whether region of interests (ROIs) detected are normal or malignant. A CADe system generally consists of four stages. The first of these stages is the post-processing phase in which images are made for noise reduction, contrast enhancement or structural improvement. In the second stage, ROIs with the possibility of mass inclusion from the enhanced images are identified. In the third stage, features are extracted from these regions for use in the classification and, if necessary, the feature selection is made. Finally, using the extracted attributes, ROIs are classified as normal, good or malignant mass. In these systems, ROIs can be considered as asymmetric regions between microcalcifications, masses, structural defects or two breasts. In addition, the whole breast area can be examined instead of looking at certain sections of the breast area for cancer detection [2].

In the literature, applications that detect masses on mammography images focus on breast region and pectoral muscle segmentation, and work on many methods, such as thresholding methods, contour-based methods and region growing methods. So, development a CADe or CADx system to detect masses in mammography images is a complex task because these systems must deal with a wide range of possibilities, such as density (fatty, glandular, dense type), shape, dimensions and margin of masses. Divyashree et al. [3] developed a system to detect breast masses using gray difference weight and maximally stable external regions (MSER) detector. In this proposed method background suppression and pectoral muscle removal stages are accomplished by gradient weight map followed by gray difference weight and fast marching. By the way, contrast limited adaptive histogram equalization (CLAHE) and decorrelation stretch methods are applied to enhance breast region. Lbachir et al. [4] proposed a CADx system to detect and classify masses. In this proposed system, an algorithm is developed to segment abnormalities. Reduction of false positive is provided using texture and shape features and the bagged trees classifier. Sarangi et al. [5] proposed a method to detect and segment breast cancer using block-based adaptive thresholding. In this paper, images are filtered by median to remove artifacts and seeded region growing algorithm is applied to remove pectoral muscle. Then, images divided into sub-images and these images are enhanced by CLAHE method. To compute a threshold, block-based adaptive thresholding method is applied to each sub-image. To segment mammograms maximum value of thresholds for each sub-image is computed. Braz Junior et al. [6] developed a methodology to detect breast cancer. To remove background and artifacts, KMeans algorithm is applied. Canny algorithm and the Hough Lines Transform is used to predict the contour that defines the edge of the pectoral muscle. CLAHE method is used to enhance the images. Then, algorithms that are MeanShift and Fast Scanning segment the images and features are extracted by spatial diversity texture analysis, geostatistical indexes, and geometrical analysis. Dhungel et al. [7] describes a system to detect, segment and classify mammography images. To detect masses and reduct false positives, random forest model and a cascade of deep learning are used. Zhu et al. [8] proposed an end-to-end trained deep multi-instance networks. In this paper, a convolutional neural network (CNN) architecture is used to obtain features. Platania et al. [9] proposed a system to detect ROIs and diagnose using CNN. Proposed system pretrains ground truth ROIs and then trains whole mammography images.

In this paper, an application that can diagnose breast cancer from mammography images is developed. The application basically consists of four stages. In the first stage of the application, noise is reduced in mammography images, and the labeled data on the mammography are removed. In the second stage of the application, the images segmented from the de-noised artificial labeling are removed from the background and all the images are prepared to the left based on the pectoral muscles. In the third stage of the application, pectoral muscles are removed from the left-based images and Zernike moments and Fast Fourier Transform (FFT) of convex mass boundary are calculated for each image. In the final stage of the application, the prediction scores are obtained from the features

Two problems in the examination of mammography images complicate the interpretation process of radiologists. One of these problems is to prevent low-contrast features on the region of interest (ROI) from being 
seen by other tissues such as bone, pectoral muscle. Another problem is that noise occurs in images during imaging or because of labeling. For noise removal, images must be subjected to appropriate filtering.

The differences in breast tissue are the differences in the grayscale of the mammography image. In mammography images, the use of regions that are suspected to contain only anomaly instead of whole breast image is more efficient in terms of reliability and time in the feature extraction stage.

In the feature extraction stage, the minimum change in the class and the maximum number of changes between classes, and minimum extraction in the number of feature is taken as the basis. This step is of great importance as the extent to which the classification success depends on how well expressed feature vectors represent the classes. In the process of obtaining feature vectors from mammography images, not only statistical methods, model based methods and pixel characteristics or signal processing methods that calculate texture features according to the frequency spectrum of the image can be used, but also mammographic features such as shape, distribution, size, contour, density, and brightness.

The classifiers selected during the classification stage, which is the last step of the classification problem, also affect the prediction scores of the classification considerably.

\section{DATABASE}

The Mammographic Image Analysis Society (MIAS) database includes 322 mammography images with 106 fat, 104 glandular, and 112 fatty tissue types, and 330 diagnoses of these images, including 207 normal, 69 benign and 54 malignant cancers [10]. Images in the database are images of 1024x1024, 8 bit/pixel resolution, mammographic images in .pgm format. The right and the left breast, breast tissue density, the presence of anomaly, the type and location of the anomaly are labeled. One example from each class in the database is shown in Figure 1 .

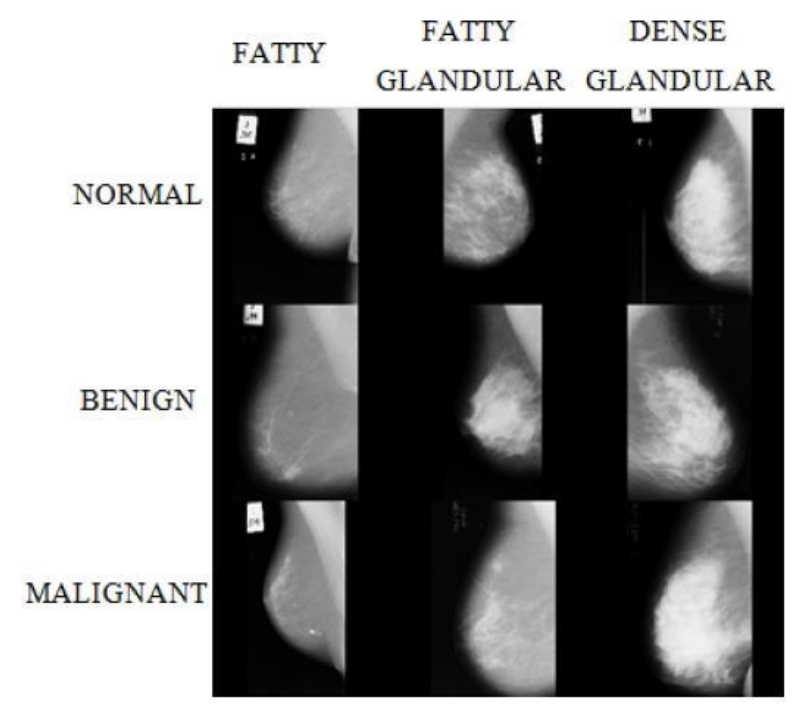

Figure 1. Sample mammography images from the MIAS database [11]

\section{EXPERIMENTAL STUDY}

Since mammography images in the MIAS database cover the entire breast, ROIs from these images must be idenified for cancer diagnosis. ROI detection is performed by considering the differences in intensity levels of pixels with the reason that ROI regions are brighter than breast parenchyma.

As shown in Figure 2, speckle noise that occurs in images during imaging, and left / right breast, CC / MLO shots of low and high intensity artificial shine in the background make the ROI detection difficult. 


\begin{tabular}{|c|c|c|}
\hline & $\begin{array}{l}\text { BŞEÜ Fen Bilimleri Dergisi } \\
8(2), 738-752,2021\end{array}$ & $\begin{array}{r}\text { BSEU Journal of Science } \\
\text { https://doi.org/10.35193/bseufbd.861211 }\end{array}$ \\
\hline ERS & & 2458-7575 (https://dergipark.org.tr/tr/pub/bseufbd) \\
\hline
\end{tabular}

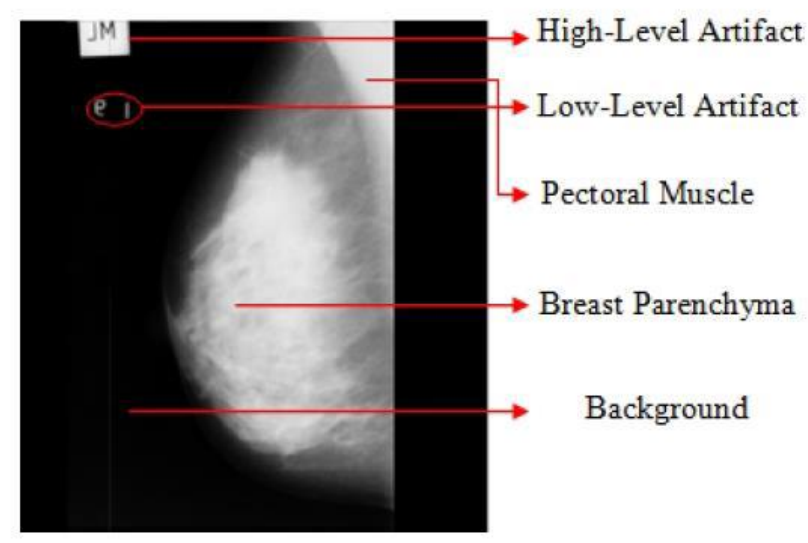

Figure 2. Mammography image [11]

\section{A. The Proposed Method for Preprocessing}

The mammography images are filtered through the median filter to eliminate noise generated during imaging. The median filter is often used for noise removal between non-linear filters [12]. With this filtering, the center pixel of the floating window that is navigated on the image is assigned to the median value of the intensity levels in that window. In this way, the large differences between the neighboring pixels are removed while the edge information is preserved. In the Algorithm 1, the general outline of the filtering algorithm is given. The input images for the algorithm can be any of the mammography images in the MIAS database. A 2-dimensional median filtering process is performed to the input images. Each output pixel contains the median value in the 3-by-3 neighborhood around the corresponding pixel in the input image. At the same time as applying this algorithm, the images are morphologically processed and the low and high density artifacts shown in Figure 2 are removed. In this step, the biggest connected component is calculated and the biggest object from the image is erased to skip high and low level artifacts. In this respect, when converting mammography images to binary level, the region with the largest area is determined because the breast area is larger than the artificial shine. The images are then crop to include the breast area and are free of background. Algorithm 2 outlines the algorithm used to compute the removed background images. The input image is assumed to have NxN image size. The output of the algorithm is an image of the breast with a removed background. It is important to calculate the cropping rectangle to remove the background.
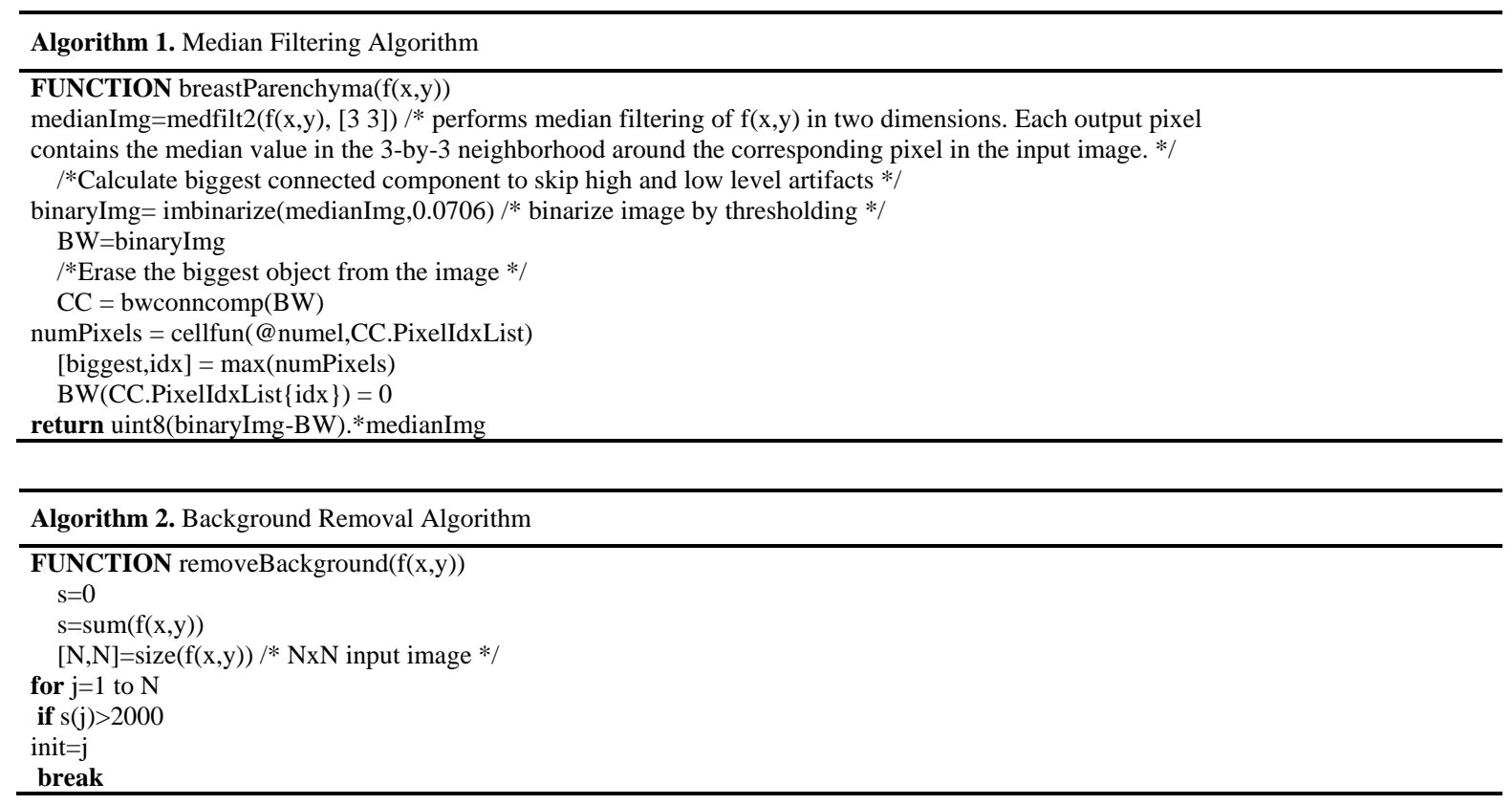


BŞEÜ Fen Bilimleri Dergisi
$8(2), 738-752,2021$ $\begin{array}{r}\text { BSEU Journal of Science } \\ \text { https://doi.org/10.35193/bseufbd.861211 }\end{array}$

After removing the background, the direction-free mammography images are determined and all images are left justified. So, the pectoral muscles are positioned in the upper left corner of the image. In the Algorithm 3 used for direction determination, sum of the first five and last five columns of the background-free binary level mammography images are calculated. If the first five columns sum is smaller than the last five columns sum, the breast region is determined to the right justified and is rendered to the left by the mirroring process [13].

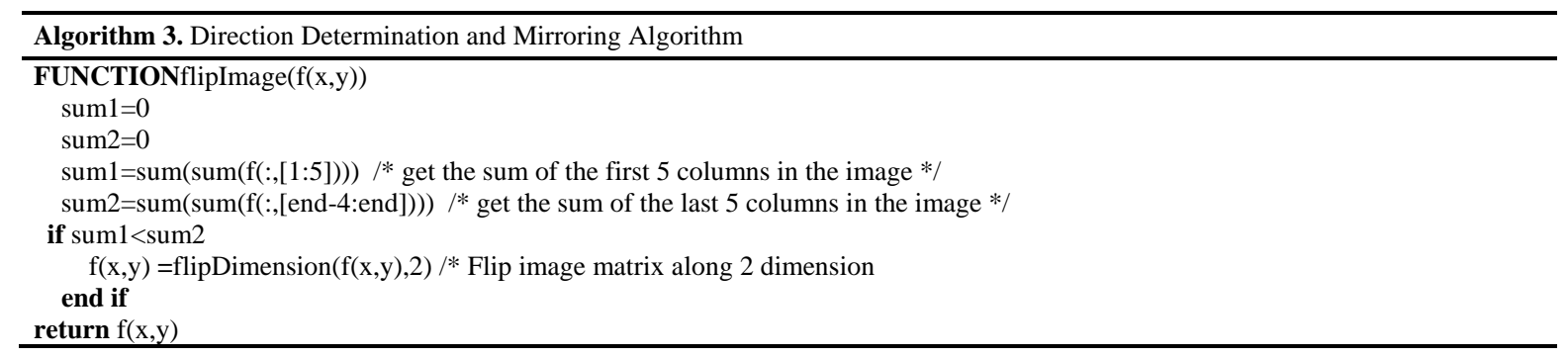

Noise and artifact removal are provided, background-free and left justified mammography images are shifted on a 10x10 floating window in the Algorithm 4 used for pectoral muscle detection. If sum of the matching pixels intensity with the floating window are greater than a threshold, the region is marked as a pectoral muscle region. In this paper, threshold is taken as 3200 because this threshold value gives the best results. In Figure 3, a sample is given that shows pectoral muscle removal process result.

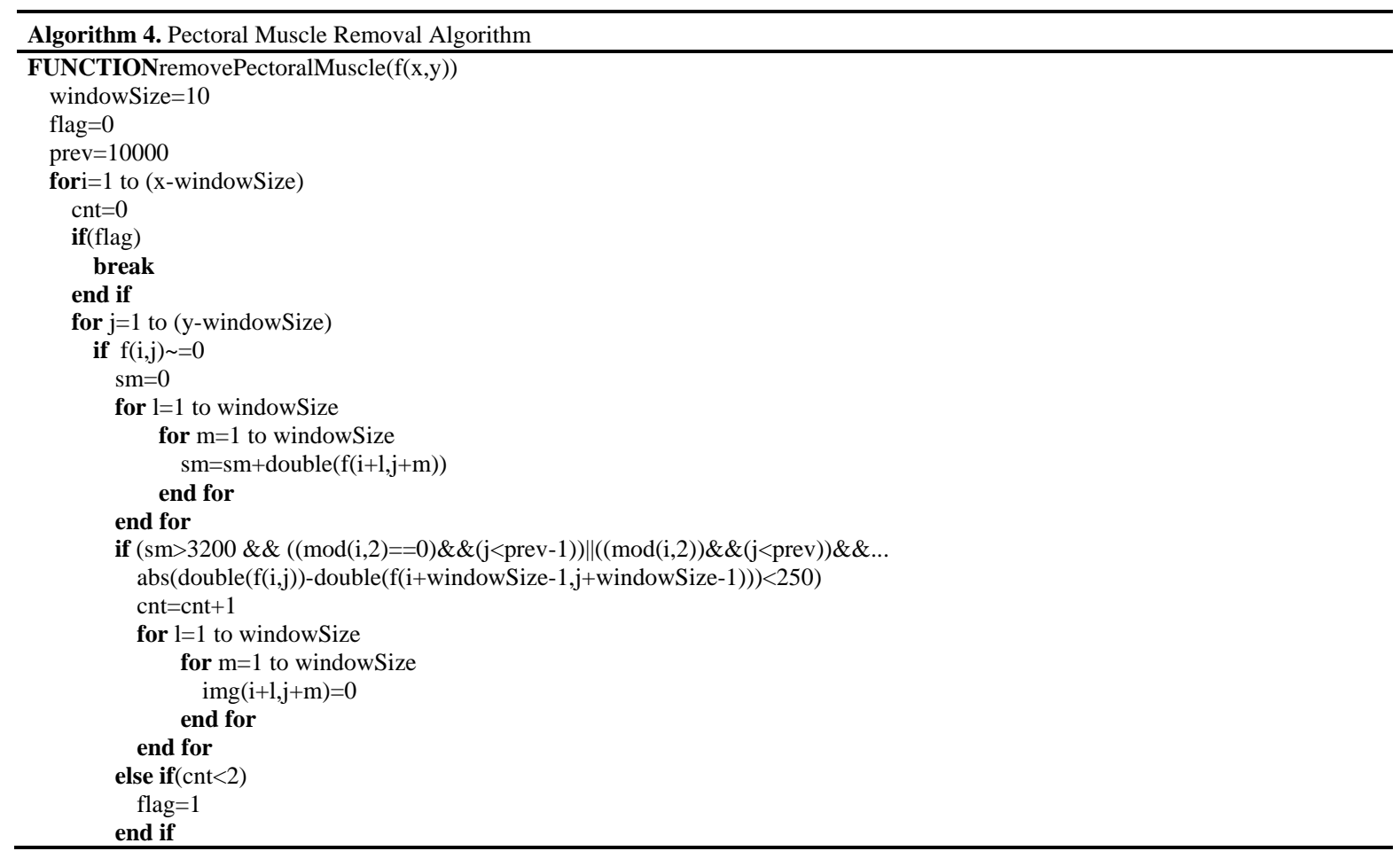




\begin{tabular}{l}
\hline BŞEÜ Fen Bilimleri Dergisi \\
$8(2), 738-752,2021$
\end{tabular}$\quad \begin{array}{r}\text { BSEU Journal of Science } \\
\hline \text { https://doi.org/10.35193/bseufbd.861211 }\end{array}$

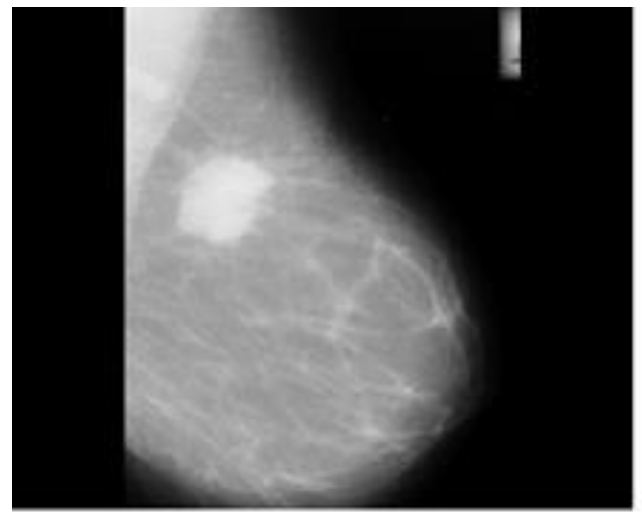

(a)

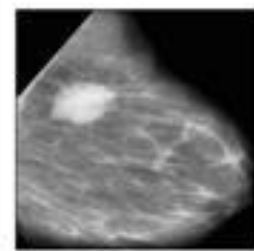

(b)

Figure 3. (a) Original image (b) pectoral muscle removed image

For the Algorithm 5 used for detection of ROI, the most recent 2000 pixel area is selected. According to algorithm if a second ROI smaller than 2000 pixel area exists, it is also selected as ROI to prevent missing smaller masses. Selected areas are taken as mask and pectoral removed image is segmented using this mask. In this algorithm input is image with removed pectoral and output is 256x256 resized segmented ROI image and ROI boundary. In Figure 4, detected ROIs are shown.

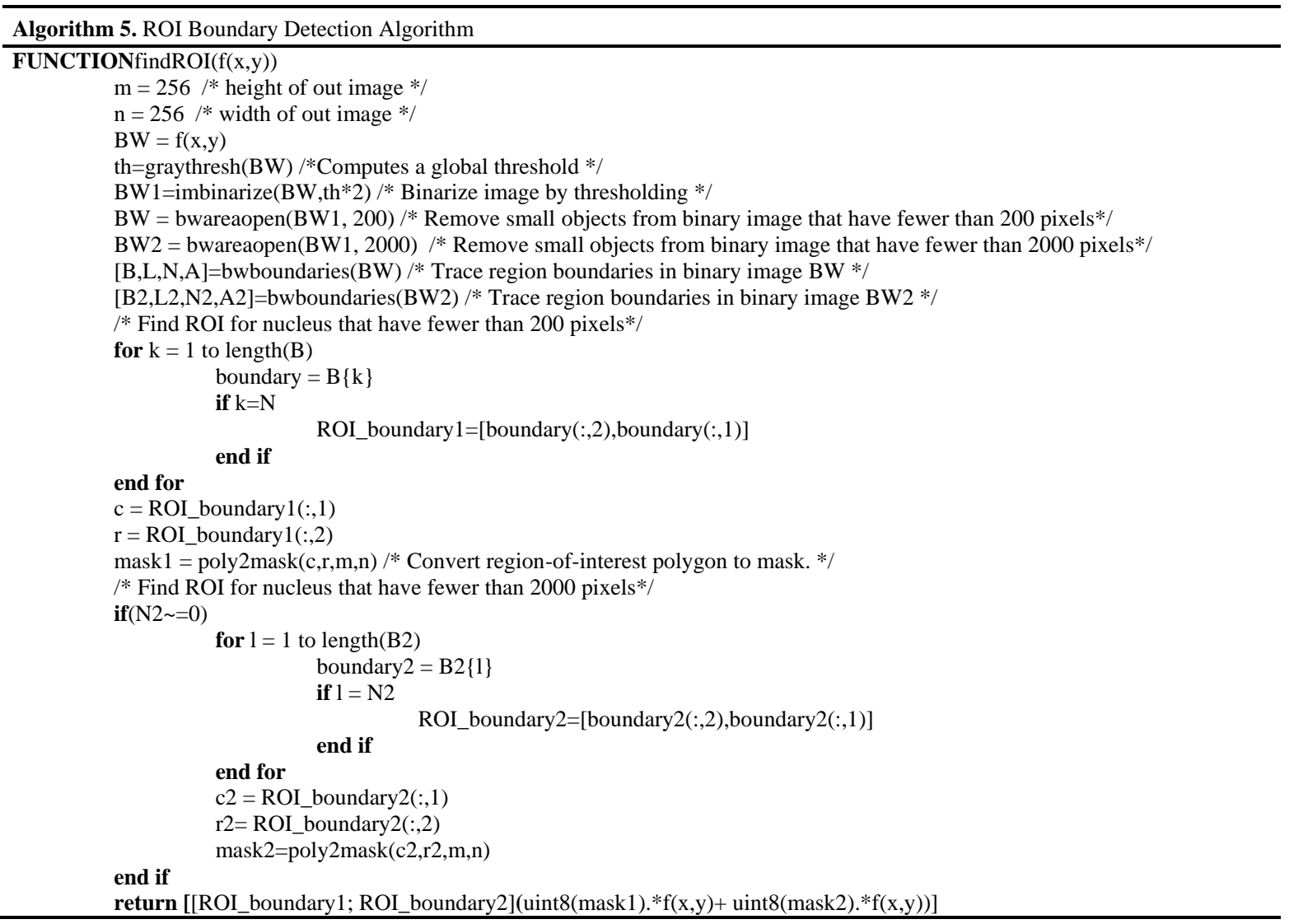



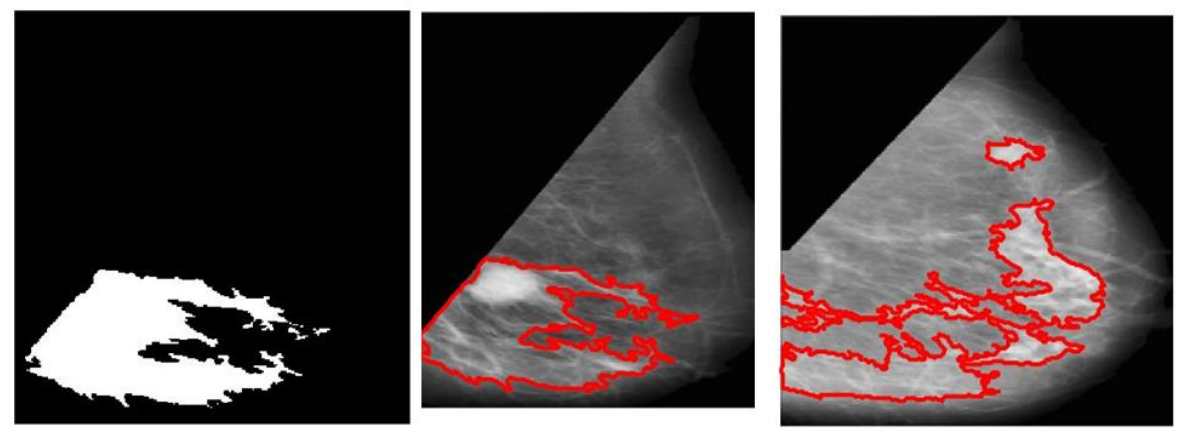

Figure 4. ROI detection from the pectoral removed image values.

At the final stage of the preprocessing, segmented ROIs' contrasts are enhanced to clarify the pixel

\section{B. The Proposed Method for Feature Extraction}

In this paper, the Zernike moments that is obtained from mammography images is used to extract rotation, scale, and translation invariant features. Zernike introduced a set of complex polynomials that form a complete orthogonal set over the interior of the unit circle, i.e. $x^{2}+y^{2}=1$. Let the set of these polynomials be denoted by $\left\{V_{n m}(x, y)\right\}$. The form of these polynomials is:

$$
V_{n m}(x, y)=V_{n m}(\rho, \theta)=R_{n m}(\rho) \exp (j m \theta)
$$

Where

$n$ Positive integer or zero.

$m$ Positive and negative integers subject to constraints $n-|m|$ even, $|m| \leq n$

$\rho$ Length of vector from origin to $(x, y)$ pixel

$\theta$ Angle between vector $\rho$ and $x$ axis in counterclockwise

$R_{n m}(\rho)$ Radial polynomial defined as:

$$
R_{n m}(\rho)=\sum_{s=0}^{n-|m| / 2}(-1)^{s} \cdot \frac{(n-s) !}{s !\left(\frac{n+|m|}{2}-s\right) !\left(\frac{n-|m|}{2}-s\right) !} \rho^{n-2 s}
$$

These polynomials are orthogonal and satisfy

$$
\iint_{x^{2}+y^{2} \leq 1}\left[V_{n m}(x, y)\right]^{*} V_{p q}(x, y) d x d y=\frac{\pi}{n+1} \delta_{n p} \delta_{m q}
$$

With

$$
\delta_{a b}=\left\{\begin{array}{rr}
1 & a=b \\
0 & \text { otherwise }
\end{array}\right.
$$

The Zernike moments are the projection of the image function onto these orthogonal basis functions. For a digital image, the Zernike moment of order $\mathrm{n}$ with repetition $\mathrm{m}$ for a continuous image function $f(x, y)$ that vanishes outside the unit circle is by replacing integrals by summations:

$$
\mathrm{A}_{\mathrm{nm}}=\frac{n+1}{\pi} \sum_{x} \sum_{y} f(x, y) V_{n m}^{*}(\rho, \theta), x^{2}+y^{2} \leq 1
$$

To compute the Zernike moments of a given image, the center of the image is taken as the origin and pixel coordinates are mapped to the range of unit circle, i.e., $x^{2}+y^{2} \leq 1$. Those pixels falling outside the unit circle are not used in the computation.

An image function $f(x, y)$ can be normalized with respect to scale and translation by transforming it into $g(x, y)$, where 


$$
g(x, y)=f\left(\frac{x}{a}+\bar{x}, \frac{y}{a}+\bar{y}\right)
$$

With $(\bar{x}, \bar{y})$ being the centroid of $f(x, y)$ and $\mathrm{a}=\sqrt{\beta / m_{00}}$, with $\beta$ a predetermined value. Wherever $(x / a+\bar{x}, y / a+\bar{y})$ does not correspond to a grid location, the function value associated with it is interpolated from the values of the four nearest grid locations around it [14].

In this paper, order of the Zernike moments is taken as 6 and in the Algorithm 6 Zernike moments are computed of the segmented ROI images. As an output of the Algorithm 6, 16 dimensional feature vector is obtained.

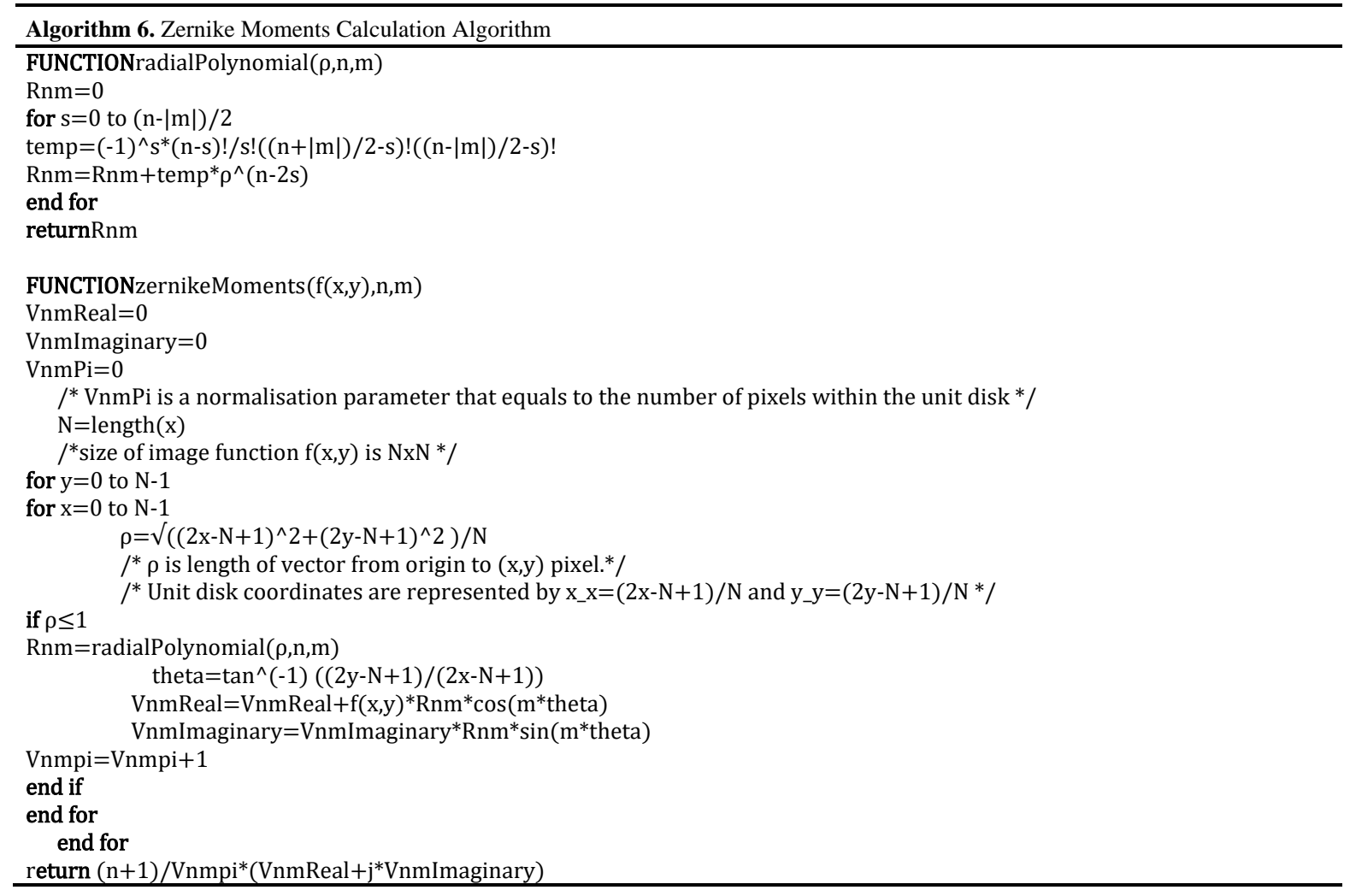

In addition, convex area enclose the ROIs is calculated and 4-point FFT of boundary of this area is taken to add feature vector. In Figure 5, convex areas enclose the ROI is shown. Finally, 20 dimensional feature vector is constructed.

After obtaining feature vectors of each image, mammography images divided into training and test sets and the labels of test sets are predicted using Discriminant Analyses, Support Vector Machines (SVM), the Nearest Neighbors (K-NN), Decision Trees and Neural Networks, respectively.

The diagram of the methods proposed in this study is shown in Figure 6.
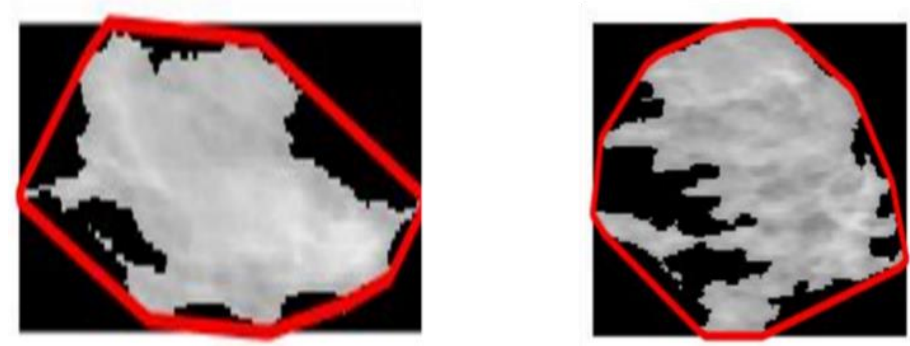

Figure 5. Convex areas enclose the ROIs 


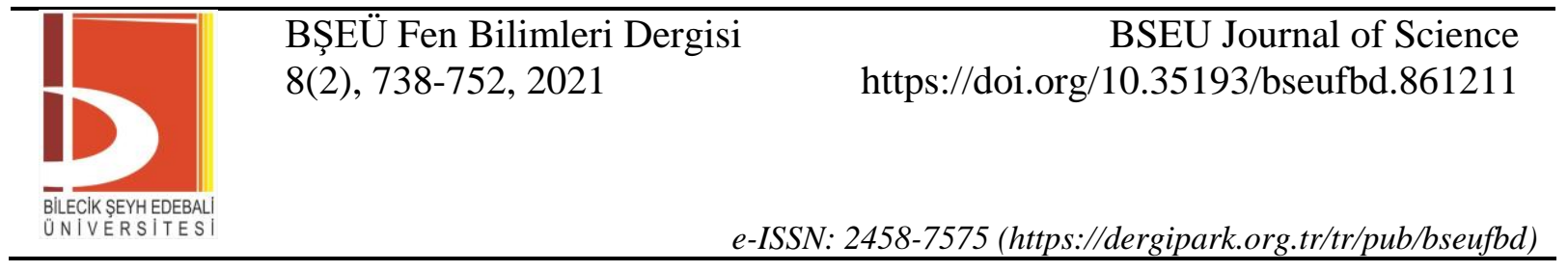

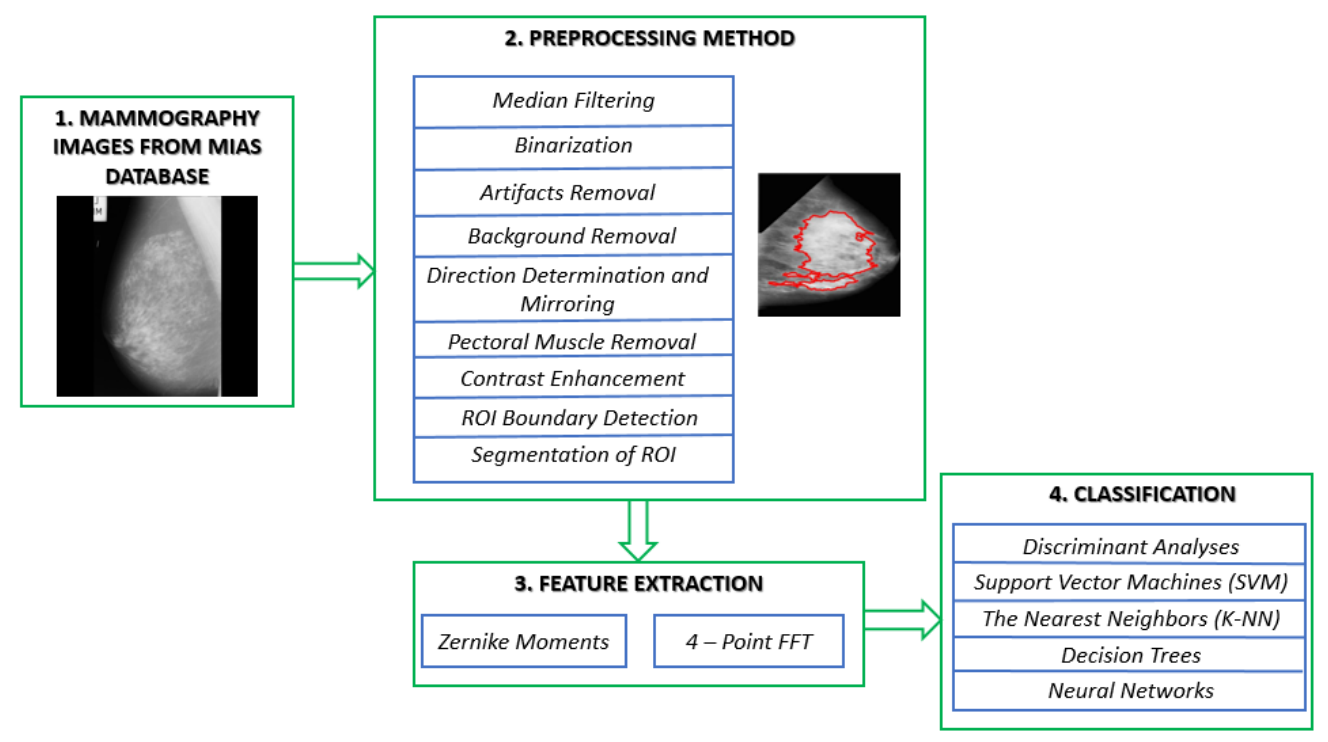

Figure 6. The diagram of the methods proposed in this study

\section{RESULTS AND DISCUSSION}

The MIAS database was taken into account to evaluate the proposed study. Preprocessing and feature extraction are done separately for 322 mammography images from the database. In the detection of masses, firstly, the stages of median filtering, binarization, artifacts removal, background removal, direction determination and mirroring, pectoral muscle removal, contrast enhancement are performed respectively in order to detect ROI boundary and segmented ROI. Figure 7 shows the original images marked with mass and obtained images after preprocessing stages. Preprocessing algorithms performed well for good quality images. However, there is an error occuring in only one image due to the original image being noisy. In Figure 8, output images during the preprocessing stage of this noisy image from MIAS database is shown. The fact that the ROI could not be determined in this image creates error in determining the mass detection in this image.

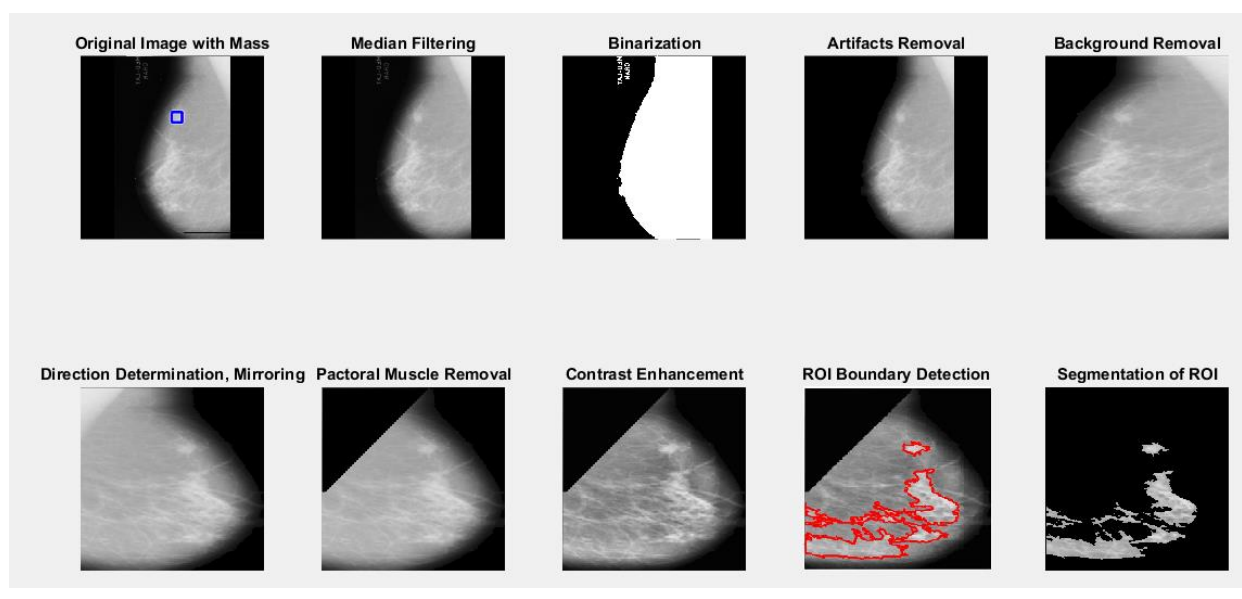

Figure 7. Preprocessing output images from good quality original image 


\begin{tabular}{|c|c|c|}
\hline & $\begin{array}{l}\text { BŞEÜ Fen Bilimleri Dergisi } \\
8(2), 738-752,2021\end{array}$ & $\begin{array}{r}\text { BSEU Journal of Science } \\
\text { https://doi.org/10.35193/bseufbd.861211 }\end{array}$ \\
\hline ERS & & 2458-7575 (https://dergipark.org.tr/tr/pub/bseufbd) \\
\hline
\end{tabular}
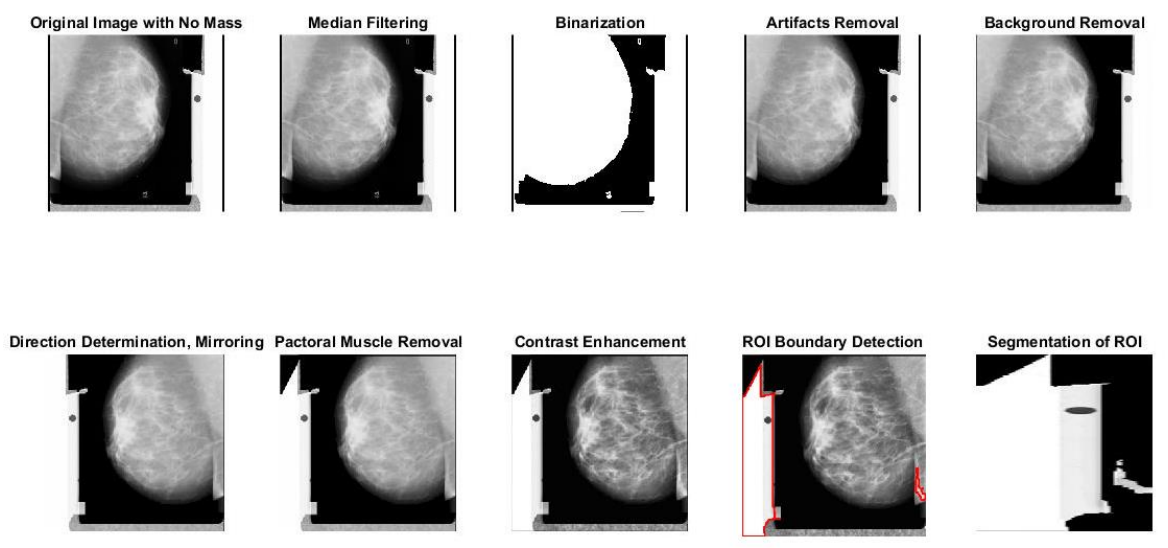

Figure 8. Preprocessing output images from a noisy original image

Four metrics sensitivity, specificity, false-positive and correctness were considered to evaluate the accuracy of the mass detection. Metrics are calculated as follows,

$$
\begin{aligned}
& \text { Sensivity }=\frac{\text { True Positive }}{\text { True Positive }+ \text { False Negative }} \\
& \text { Specificity }=\frac{\text { True Negative }}{\text { True Negative }+ \text { False Positive }} \\
& \text { False }- \text { positive rate }=\frac{\text { False Positive }}{\text { False Positive }+ \text { True Negative }} \\
& \text { Correctness }=\frac{\text { True Positive }}{\text { True Positive }+ \text { False Positive }} \\
& \text { Accuracy }=\frac{\text { True Positive }+ \text { True Negative }}{\text { True Negative }+ \text { False Positive }+ \text { True Negative }+ \text { False Negative }}
\end{aligned}
$$

In terms of detection of mass in this paper, true-positive represents the actual no-mass class predicted as no-mass. True-negative represents the actual mass class predicted as mass. False-positive represents the actual no-mass class predicted as mass. False-negative represents the actual mass class predicted as no-mass. Basically, 5 different classifiers are used to calculate the mentioned metrics. These classifiers are Discriminant Analyses, Support Vector Machines (SVM), the nearest neighbors (K-NN), Decision Trees and Neural Networks, respectively.

In discriminant analyses, Linear Discriminant Analysis (LDA) and Quadratic Discriminant Analysis (QDA) are applied to predict the class of test set. In Table 1, the average values of sensitivities, specificities, falsepositive rates, correctnesses and accuracies are displayed of LDA and QDA.

To classify the same test set with SVM, Linear SVM, Quadratic SVM, Cubic SVM, Fine Gaussian SVM, Medium Gaussian SVM and Course Gaussian SVM classifiers are applied. Kernel functions of Linear, Quadratic, Cubic and Gaussians SVM are Linear, Quadratic, Cubic, and Gaussians, respectively. Kernel scales of Fine, Medium, and Coarse Gausssian SVM are 1.1, 4.5, and 18, respectively. In Table 2, the average values of sensitivities, specificities, false-positive rates, correctnesses and accuracies are displayed of Linear, Quadratic, Cubic, Fine Gaussian, Medium Gaussian, and Course Gaussian SVM.

To classify the same test set with K-NN, Fine K-NN, Medium K-NN, Coarse K-NN, Cosine K-NN, Cubic K-NN, and Weighted K-NN are applied. Fine K-NN model type is that number of neighbors is 1, distance metric is Euclidean and distance weight is equal. Medium K-NN model type is that number of neighbors is 10 , distance metric is Euclidean and distance weight is equal. Coarse K-NN model type is that number of neighbors is 100 , distance metric is Euclidean and distance weight is equal. Cosine K-NN model type is that number of neighbors is 10 , distance metric is cosine and distance weight is equal. Cubic K-NN model type is that number of neighbors is 10, distance metric is Minkowski (cubic) and distance weight is equal. Weighted K-NN model type is that number of neighbors is 10, distance metric is Euclidean and distance weight is squared inverse. Table 3 
displays the average values of sensitivities, specificities, false-positive rates, correctnesses and accuracies of Fine, Medium, Coarse, Cosine, Cubic, and Weighted K-NN.

To classify he same test set with Decision Tree, Complex Tree, Medium Tree, and Simple Tree are applied. Maximum numbers of splits of Complex, Medium, and Simple Tree are 100, 20, and 4, respectively. Table 4 displays the average values of sensitivities, specificities, false-positive rates, correctnesses and accuracies of Complex, Medium, and Simple Tree.

To classify the 20-dimensional feature vector for 322 observers with Neural Network, a pattern recognition neural network is defined. Figure 9 shows the architecture of Neural Network.322 samples are divided up randomly for $70 \%$ (226 samples) training, 15\% (48 samples) validation, and 15\% (48 samples) testing. Numbers of hidden neurons are adjusted 1, 10, and 15. Figure 10, Figure 11, and Figure 12 shows training, validation, test and all confusion matrixes of neural network with the numbers of hidden neurons as $1,10,15$, respectively. Table 5 displays the all average values of sensitivities, specificities, false-positive rates, correctnesses and accuracies of Neural Networks.

According to simulation results, the best classifiers for the proposed method with the accuracy rate $100.0 \%$ are Fine Gaussian SVM, Fine K-NN, and Weighted K-NN. 20-dimensional feature vector data for 322 observers not linearly separable. Because of that, accuracy ratio is decrease if classifiers are linear classifier. When order of function of classifiers is increased or with the higher dimensional transformations by kernel function, accuracy ratio is increase.

Table 1. Metrics rate of Discriminant Analyses

\begin{tabular}{lcc}
\hline & $\begin{array}{c}\text { Linear } \\
\text { Discriminant }\end{array}$ & $\begin{array}{c}\text { Quadratic } \\
\text { Discriminant }\end{array}$ \\
\hline Sensivity (\%) & 66.9 & 81.3 \\
Specificity (\%) & 53.7 & 60.8 \\
False-positive rate (\%) & 46.3 & 39.2 \\
Correctness (\%) & 90.82 & 75.4 \\
Accuracy (\%) & 65.2 & 73.0 \\
\hline
\end{tabular}

Table 2. Metrics rate of SVMs

\begin{tabular}{lcccccc}
\hline & $\begin{array}{c}\text { Linear } \\
\text { SVM }\end{array}$ & $\begin{array}{c}\text { Quadratic } \\
\text { SVM }\end{array}$ & $\begin{array}{c}\text { Cubic } \\
\text { SVM }\end{array}$ & $\begin{array}{c}\text { Fine Gaussian } \\
\text { SVM }\end{array}$ & $\begin{array}{c}\text { Medium Gaussian } \\
\text { SVM }\end{array}$ & $\begin{array}{c}\text { Coarse Gaussian } \\
\text { SVM }\end{array}$ \\
\hline Sensivity (\%) & 64.3 & 80.0 & 93.6 & $\mathbf{1 0 0 . 0}$ & 69.0 & 64.3 \\
Specificity (\%) & 0.0 & 94.1 & 99.0 & $\mathbf{1 0 0 . 0}$ & 92.0 & 0.0 \\
False-positive rate (\%) & 0.0 & 5.9 & 1.0 & $\mathbf{0 . 0}$ & 8.0 & 0.0 \\
Correctness (\%) & 100.0 & 98.1 & 99.5 & $\mathbf{1 0 0 . 0}$ & 99.0 & 100.0 \\
Accuracy (\%) & 64.3 & 82.9 & 95.3 & $\mathbf{1 0 0 . 0}$ & 70.8 & 64.3 \\
\hline
\end{tabular}

Table 3. Metrics rate of K-NNs

\begin{tabular}{|c|c|c|c|c|c|c|}
\hline & $\begin{array}{c}\text { Fine } \\
\text { K-NN }\end{array}$ & $\begin{array}{c}\text { Medium } \\
\text { K-NN }\end{array}$ & $\begin{array}{l}\text { Coarse } \\
\text { K-NN }\end{array}$ & $\begin{array}{c}\text { Cosine K- } \\
\text { NN }\end{array}$ & $\begin{array}{l}\text { Cubic } \\
\text { K-NN }\end{array}$ & $\begin{array}{c}\text { Weighted } \\
\text { K-NN }\end{array}$ \\
\hline Sensivity (\%) & 100.0 & 67.4 & 64.3 & 66.7 & 67.2 & 100.0 \\
\hline Specificity (\%) & 100.0 & 64.5 & 0.0 & 64.0 & 62.5 & 100.0 \\
\hline False-positive rate $(\%)$ & 0.0 & 35.5 & 0.0 & 36.0 & 37.5 & 0.0 \\
\hline Correctness (\%) & 100.0 & 94.7 & 100.0 & 91.6 & 94.2 & 100.0 \\
\hline Accuracy $(\%)$ & 100.0 & 67.1 & 64.3 & 66.5 & 66.8 & 100.0 \\
\hline
\end{tabular}




\begin{tabular}{|c|c|c|}
\hline & $\begin{array}{l}\text { BŞEÜ Fen Bilimleri Dergisi } \\
8(2), 738-752,2021\end{array}$ & $\begin{array}{r}\text { BSEU Journal of Science } \\
\text { https://doi.org/10.35193/bseufbd.861211 }\end{array}$ \\
\hline $\begin{array}{l}\text { BiLECIKSEYYH EDEBALI } \\
\text { UNIVERSITESI }\end{array}$ & & 2458-7575 (https://dergipark.org.tr/tr/pub/bseufbd) \\
\hline
\end{tabular}

Table 4. Metrics rate of Decision Trees

\begin{tabular}{lccc}
\hline & $\begin{array}{c}\text { Complex } \\
\text { Tree }\end{array}$ & $\begin{array}{c}\text { Medium } \\
\text { Tree }\end{array}$ & $\begin{array}{c}\text { Simple } \\
\text { Tree }\end{array}$ \\
\hline Sensivity (\%) & 92.2 & 83.3 & 72.6 \\
Specificity (\%) & 93.3 & 77.2 & 58.8 \\
False-positive rate (\%) & 6.7 & 22.8 & 41.2 \\
Correctness (\%) & 96.6 & 88.9 & 83.1 \\
Accuracy (\%) & 92.5 & 81.4 & 68.9 \\
\hline
\end{tabular}

Table 5. Metrics rate of Neural Networks

\begin{tabular}{lccc}
\hline & $\begin{array}{c}\text { Neural Network } \\
\text { (\# of Hidden Neurons=1) }\end{array}$ & $\begin{array}{c}\text { Neural Network } \\
\text { (\# of Hidden Neurons=10) }\end{array}$ & $\begin{array}{c}\text { Neural Network } \\
\text { (\# of Hidden Neurons=15) }\end{array}$ \\
\hline Sensivity (\%) & 97.6 & 88.9 & 91.3 \\
Specificity (\%) & 9.6 & 13.0 & 16.5 \\
False-positive rate (\%) & 90.4 & 87.0 & 83.5 \\
Correctness (\%) & 66.0 & 64.8 & 66.3 \\
Accuracy (\%) & 66.1 & 61.8 & 64.6 \\
\hline
\end{tabular}

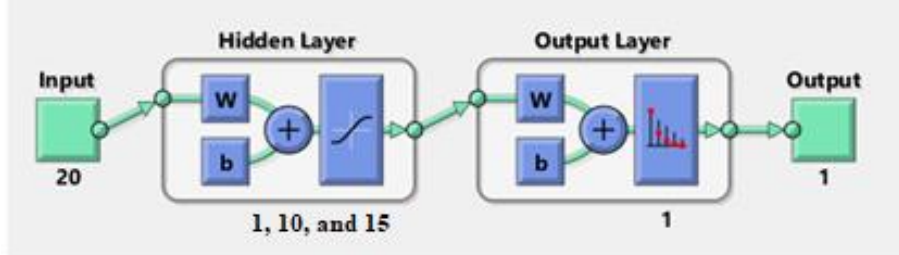

Figure 9. Architecture of Neural Network
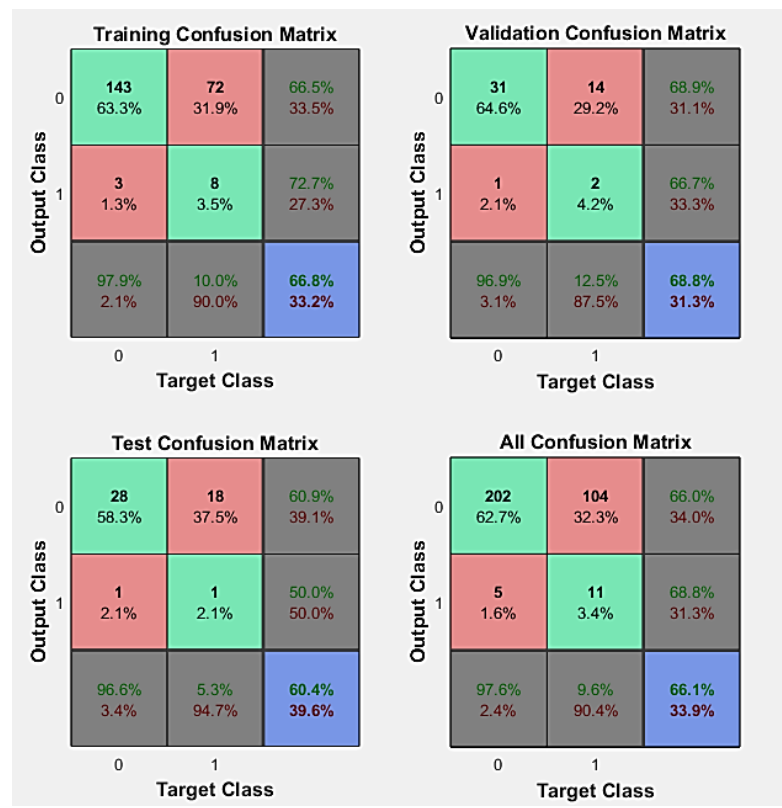

Figure 10. Training, validation, test and all confusion matrix of Neural Network (number of hidden neurons=1) 

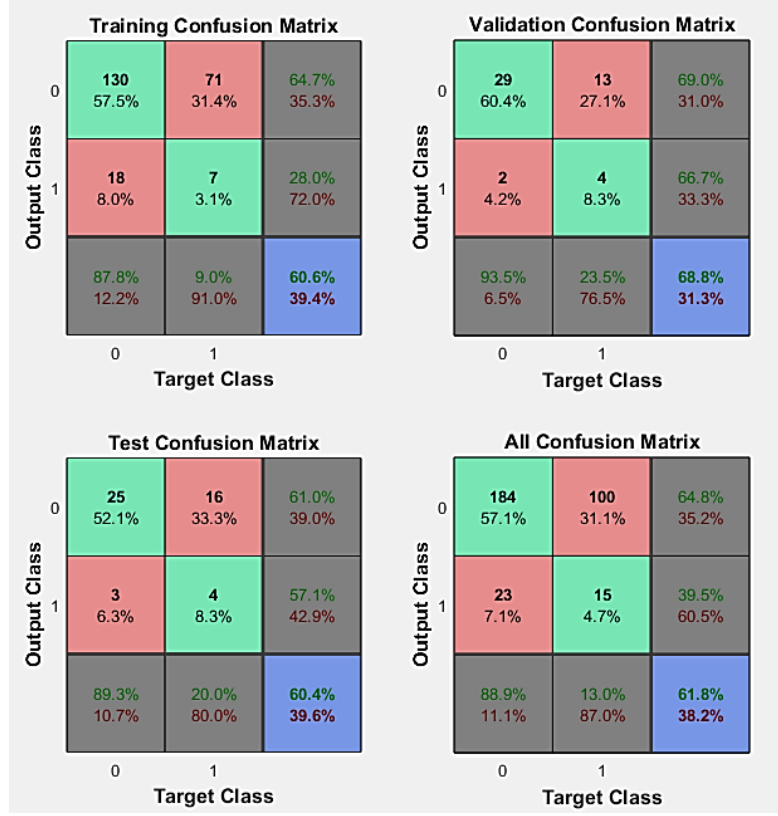

Figure 11. Training, validation, test and all confusion matrix of Neural Network (number of hidden neurons=10)
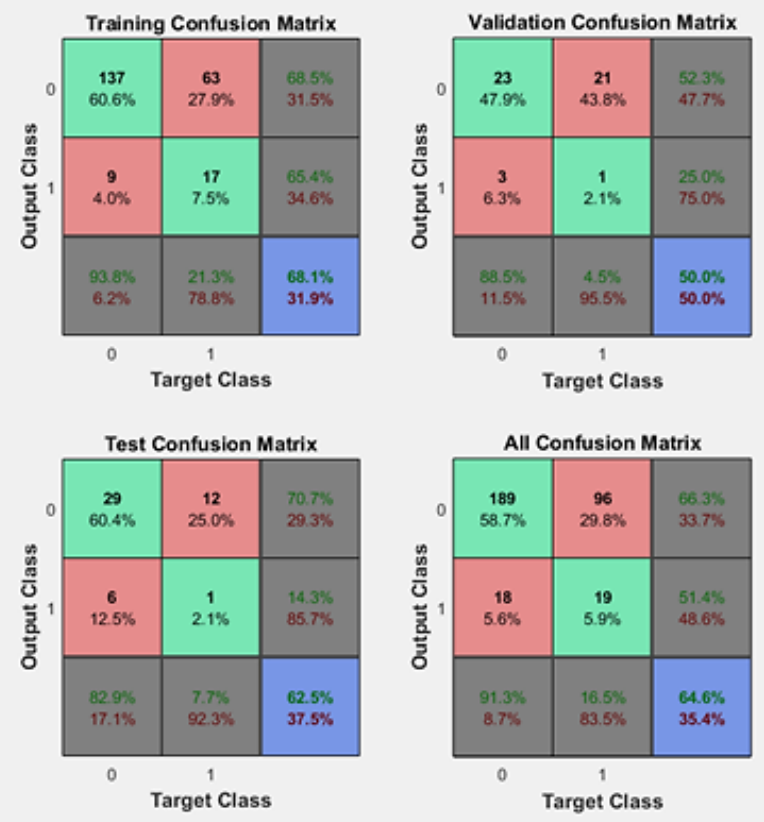

Figure 12. Training, validation, test and all confusion matrix of Neural Network (number of hidden neurons=15)

In comparison with the state-of-the-art methods, the accuracies of detection of breast masses are listed in Table 6. Table 6 displays that accuracy of the proposed method gives best result where compared to other studies. 


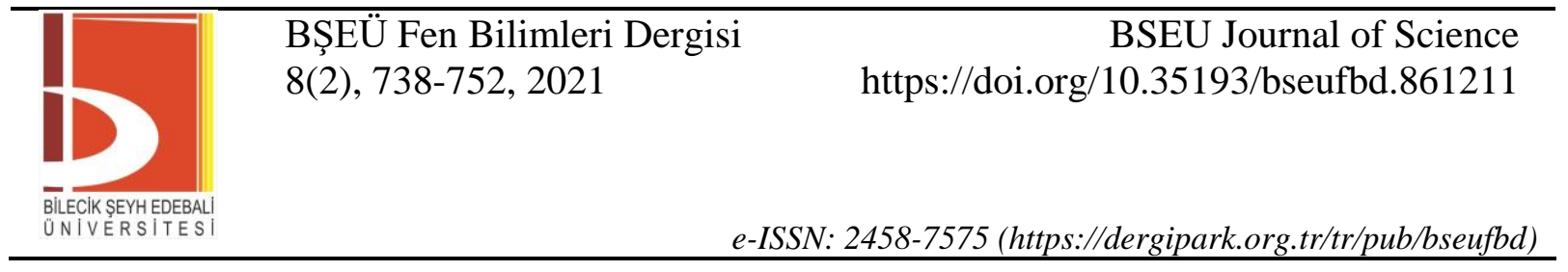

Table 6. Comparative study with the methods cited in section 1 on detection of mass

\begin{tabular}{llll}
\hline Detection Method & Author(s) & Dataset & Accuracy (\%) \\
\hline Zernike moments and FFT of convex mass shapes & Proposed method & MIAS & 100.0 \\
Gray difference weight and MSER detector & {$[3]$} & MIAS & 97.64 \\
Automatic computer-aided diagnosis system & {$[4]$} & MIAS & 94.2 \\
Legendre neural network-based optimal threshold & {$[5]$} & MIAS & 96 \\
Spatial diversity, geostatistics, and concave geometry & {$[6]$} & MIAS & 97.3 \\
Bounding box CNN detection & {$[7]$} & INBreast & 95.0 \\
Deep multi-instance networks & {$[8]$} & INBreast & 92.0 \\
Deep learning and region of interest & {$[9]$} & DDSM & 93.5 \\
\hline
\end{tabular}

\section{CONCLUSION}

In this paper, a CAD system detects mass in mammography images from the Zernike moments and FFT of convex mass shapes is proposed. During the development of the application, the MIAS database, which is available to the researchers, is used. After post processing, pectoral muscles, which have similar features as ROIs, are removed from images to prevent low-accuracy rate in the classification step. After the ROIs are detected, feature vectors from the Zernike moments and FFT of convex mass shapes are extracted. Finally, using Discriminant Analyses, Support Vector Machines, the Nearest Neighbors, Decision Trees and Neural Networks, labels of test images are predicted. According to simulation results, the best classifiers for the proposed method with the accuracy rate 100.0\% are Fine Gaussian SVM, Fine K-NN, and Weighted K-NN.

Although Computer-Aided Detection (CAD) systems are controversially argued not only in scientific communities but also in several health institutions, it is obviously proved that adding CAD systems to single reading of mammograms is more successful than double reading of mammograms especially on the accuracy rate of cancer detection. Therefore, CAD systems are continuously progressing in mammography screening. In this study, a very critical step, which is the determination of suspicious regions in mammography images, is efficiently achieved so that a smart tool is planned to implement for supporting radiologists since the workload for them is enormously high and continues to increase. This step is a pre-step before resolving suspicious regions in mammography images whether they include malignant or benign tumors.

\section{REFERENCES}

[1] Jemal, A., Bray, F., Center, M. M., Ferlay, J., Ward, E., \& Forman, D. (2011). Global cancer statistics. CA: a cancer journal for clinicians, 61(2), 69-90. https://doi.org/10.3322/caac.20107

[2] Zhang, Z., Lu, J., \& Yip J. (2008). Computer aided mammography. In: Proceedings of Computing and Engineering Annual Researchers' Conference 2008: CEARC'08, University of Huddersfield, Huddersfield, 125-130. ISBN 978-1-86218-067-3.

[3] Divyashree, B. \& Kumar, G. (2021). Breast Cancer Mass Detection in Mammograms Using Gray Difference Weight and MSER Detector. SN Computer Science, 2. 10.1007/s42979-021-00452-8.

[4] Lbachir, I. A., Daoudi, I., \& Tallal, S. (2020). Automatic computer-aided diagnosis system for mass detection and classification in mammography. Multimedia Tools and Applications, 80(6), 9493-9525. https://doi.org/10.1007/s11042-020-09991-3

[5] Sarangi, S., Rath, N. P., \& Sahoo, H. K. (2021). Mammogram mass segmentation and detection using Legendre neural network-based optimal threshold. Medical \& Biological Engineering \& Computing, 59(4), 947-955. https://doi.org/10.1007/s11517-021-02348-4

[6] Braz Junior, G., da Rocha, S. V., de Almeida, J. D. S., de Paiva, A. C., Silva, A. C., \& Gattass, M. (2018). Breast cancer detection in mammography using spatial diversity, geostatistics, and concave geometry. Multimedia Tools and Applications, 78(10), 13005-13031. https://doi.org/10.1007/s11042-018-6259-z

[7] Dhungel, N., Carneiro, G., \& Bradley, A. P. (2017). A deep learning approach for the analysis of masses in mammograms with minimal user intervention. Medical Image Analysis, 37, 114-128. https://doi.org/10.1016/j.media.2017.01.009 
[8] Zhu, W., Lou, Q., Vang, Y. S., \& Xie, X. (2017). Deep Multi-instance Networks with Sparse Label Assignment for Whole Mammogram Classification. Medical Image Computing and Computer Assisted Intervention - MICCAI 2017, 603-611. https://doi.org/10.1007/978-3-319-66179-7_69

[9] Platania, R., Shams, S., Yang, S., Zhang, J., Lee, K., \& Park, S. J. (2017). Automated Breast Cancer Diagnosis Using Deep Learning and Region of Interest Detection (BC-DROID). Proceedings of the 8th ACM International Conference on Bioinformatics, Computational Biology, and Health Informatics, 536-543. https://doi.org/10.1145/3107411.3107484

[10] Suckling, J., et al (1994). The Mammographic Image Analysis Society Digital Mammogram Database Exerpta Medica. International Congress Series, 1069, 375-378.

[11] Esener, İ., Ergin, S., \& Yüksel, T. (2018). A novel multistage system for the detection and removal of pectoral muscles in mammograms. Turkish Journal of Electrical Engineering and Computer Science, 26 (1), 35-49.

[12] Gallagher, N., \& Wise, G. (1981). A theoretical analysis of the properties of median filters. IEEE Transactions on Acoustics, Speech, and Signal Processing, 29(6), 1136-1141. https://doi.org/10.1109/tassp.1981.1163708

[13] Nagi, J., Kareem, S. A., Nagi, F., \& Ahmed, S. K. (2010). Automated breast profile segmentation for ROI detection using digital mammograms. 2010 IEEE EMBS Conference on Biomedical Engineering and Sciences (IECBES), 87-92. doi:10.1109/iecbes.2010.5742205.

[14] Khotanzad, A., \& Hong, Y. (1990). Invariant image recognition by Zernike moments. IEEE Transactions on Pattern Analysis and Machine Intelligence, 12(5), 489-497. doi:10.1109/34.55109 